\title{
Multi-Mode Voltage Sag/Swell Generator Based on Three-Phase Inverter Circuit
}

\author{
Qiguo Han ${ }^{1}$, Xing Wang ${ }^{1}$, Pengfei $\mathrm{Hu}^{2, *}$, Maolin Wang ${ }^{1}$, Xu Luo ${ }^{1}$ and Weihua Hou ${ }^{1}$ \\ 1 School of Automation, Hangzhou Dianzi University, Hangzhou 310018, China; hanqiguo@hdu.edu.cn (Q.H.); \\ 142060135@hdu.edu.cn (X.W.); 161060079@hdu.edu.cn (M.W.); 172060059@hdu.edu.cn (X.L.); \\ 181060076@hdu.edu.cn (W.H.) \\ 2 College of Electrical Engineering, Zhejiang University, Hangzhou 310027, China \\ * Correspondence: hpf@zju.edu.cn; Tel.: +86-13658095156
}

Citation: Han, Q.; Wang, X.; Hu, P.; Wang, M.; Luo, X.; Hou, W. Multi-Mode Voltage Sag/Swell Generator Based on Three-Phase Inverter Circuit. Energies 2021, 14 , 6520. https://doi.org/10.3390/ en14206520

Academic Editor: Juri Belikov

Received: 11 September 2021

Accepted: 5 October 2021

Published: 11 October 2021

Publisher's Note: MDPI stays neutral with regard to jurisdictional claims in published maps and institutional affiliations.

Copyright: (c) 2021 by the authors. Licensee MDPI, Basel, Switzerland. This article is an open access article distributed under the terms and conditions of the Creative Commons Attribution (CC BY) license (https:// creativecommons.org/licenses/by/ $4.0 /)$.

\begin{abstract}
The voltage ride through capability of the major auxiliary variable-frequency drive (VFD) in large thermal power plants is the key technical issue of power grid and source coordination. In order to test the high voltage ride through (HVRT) and low voltage ride through (LVRT) capability of the auxiliary VFD, it is necessary to develop a power supply to simulate different grid voltage sag and swell accurately. In this paper, a generator (VSSG) based on the common three-phase inverter circuit that can simulate multi-mode voltage sag/swell is proposed. The designed main circuit consisting of transformer, rectifier, DC split capacitors, three-phase inverter, and LC-filter can generate single-phase and three-phase voltage sag, swell, and phase angle jumping flexibly. The developed control strategies composed of the double closed-loop control and the neutral voltage balance control achieve accurate output, fast dynamic response, and step-less adjustment. Simulation and experiment results verify the multi-mode voltage simulation performances of the proposed VSSG, which can be effectively used to emulate power grid voltage sag and swell phenomena under the IEEE 1159 and IEC standards.
\end{abstract}

Keywords: voltage sag/swell generator (VSSG); voltage sag; voltage swell; voltage phase angle jumping; three-phase inverter circuit

\section{Introduction}

Voltage sag and swell are the common phenomena of power grid. Voltage sag is caused by grid short circuit, access of large capacity load and the dual power supply switching, etc. Additionally, voltage swell is caused by a reduction in large capacity load, a large capacitor compensator putting into operation and power system oscillation, etc. For a specific low-voltage electric equipment, it will encounter voltage sag/swell resulting not only from its own distribution system faults, but from faults propagated from transformers, power lines, and other loads in distance. Therefore, the diversity of the voltage sag/swell characteristics should be considered.

When the electric equipment encounters voltage sag or swell, its operation status is disturbed. Similar to the major auxiliary variable-frequency drives (VFD) in a large thermal power plant, to achieve operation coordination of the power grid and source, the high voltage ride through (HVRT) and low voltage ride through (LVRT) capability of the auxiliary VFD in the power plant need to be verified. Therefore, it is necessary to develop a power supply to simulate voltage sag/swell accurately, which is the basis and verification means for the HVRT and LVRT support equipment research [1-3]. At present most research is focused on the simulation of the grid voltage sag, i.e., voltage sag generator (VSG), which is mostly used in the field of wind power system test [4,5], power quality improvement in wind farm [6] and DC supply system [7], and other renewable energy systems [8-10].

The common VSG solutions can be categorized as shunt-impedance-based, synchronousgenerator-based, transformer-based, and power-electronics-converter-based. The shunt- 
impedance-based VSG [11-13] uses shunt and series impedances in its main circuit. The series impedance is used to suppress the current impact, and the shunt impedance is used to generate voltage sag. The voltage sag depth and duration are adjusted by controlling the shunt impedance value and its time of switching into the circuit. This method is simple and easy to implement, but it has the drawbacks of large energy consumption, low accuracy, and adjustment discontinuity. The synchronous-generator-based VSG can simulate the load side voltage sags by changing the exciting current, which has the drawbacks of slow response, only symmetrical faults emulation, relatively large weight, and high cost [14,15]. The transformer-based VSG is implemented by constructing the output voltage switchover of the autotransformer to simulate the actual grid voltage sag [16-19]. The switchover device usually uses contactor or the non-contact fast switch constructed by bidirectional thyristor or insulated gate bipolar transistor (IGBT). It is difficult to achieve precise control of voltage transient variation. Additionally, unexpected high impulse current and spike voltage are usually accompanied during the period of simulating voltage sag.

Comparatively, the power-electronics-converter-based grid voltage sag or swell generator deserves more attention, which is mostly on the basis of inverter circuit [5,20-25]. A comprehensive overview on cause classification of voltage sag and voltage sag emulators and applications is presented in [26]. With the improvement of topology and control scheme embedded, the voltage conversion can simulate all kinds of grid voltage sag or swell. This solution has many advantages over the foregoing solutions, such as quicker response, flexible control, and step-less output adjustment. The matrix-converter-based sag/swell generator is also a good solution [27-29], but its output modes are fewer than the inverter-based. In [24], a method using three single-phase inverters is proposed to achieve any phase voltage sag, but its circuit structure is relatively complex.

In view of the above, this paper presents a new voltage sag/swell generator (VSSG) based on the common three-phase inverter circuit and SPWM control, which can emulate multi-mode of voltage sag/swell and phase angle jumping. Corresponding technical performance and hardware structure comparison with other power-electronics-converterbased voltage sag/swell generator are shown in Table 1. Topology in [20,21] employs series transformer and auxiliary semiconductor devices, while topology in [22] employs four power legs. Comparatively, with simpler main circuit, more features and low cost, the VSSG proposed is a more perfect and practical than others.

Table 1. Comparison of various voltage sag/swell generators.

\begin{tabular}{cccc}
\hline & $\begin{array}{c}\text { Three Single-Phase- } \\
\text { Inverters-Based [22] }\end{array}$ & $\begin{array}{c}\text { 3-Phase 3-Wire 4-Legs } \\
\text { Inverter-Based [20,21] }\end{array}$ & $\begin{array}{c}\text { Proposed 3-Phase 4-Wire } \\
\text { Inverter with Neutral Control }\end{array}$ \\
\hline Circuit structure & Complex & Less complex & Simple \\
No. of IGBT & 12 & 8 & 6 \\
Step-less adjustment & Yes & Yes & Yes \\
Angle jumping & No & No & Yes \\
Voltage Swell & No & No & Yes \\
Cost & High & High & Low \\
\hline
\end{tabular}

The rest of this paper is organized as follows. The grid voltage sag/swell features under different grid faults and fault propagation that need to be simulated are firstly introduced in Section 2. Section 3 presents the main circuit and its mathematical models of the proposed VSSG and Section 4 illustrates the designed control strategy. Simulation and experimental test results of the VSSG are depicted in Sections 5 and 6, respectively. Section 7 concludes the paper.

\section{The Grid-Fault and Its Propagation}

VSSG is designed to accurately simulate all kinds of faults in the power system. Therefore, it is necessary to consider the actual situation, i.e., the diversity of faults in the actual grid and the changes of fault features after propagation. The voltage sag/swell 
features mainly include the amplitude of voltage sag/swell, sag/swell duration, fault frequency, and the voltage phase angle jump [30,31].

When line faults occur, the eigenvector diagrams of phase voltage at the point of common coupling (PCC) in relation to different neutral grounding modes are shown in Table 2. As the figures show in Table 2, the dotted line is the voltage amplitude and phase of each phase under normal condition, while the solid line indicates the voltage amplitude and phase corresponding to each phase fault.

Table 2. Phase voltage eigenvector diagram of different faults.

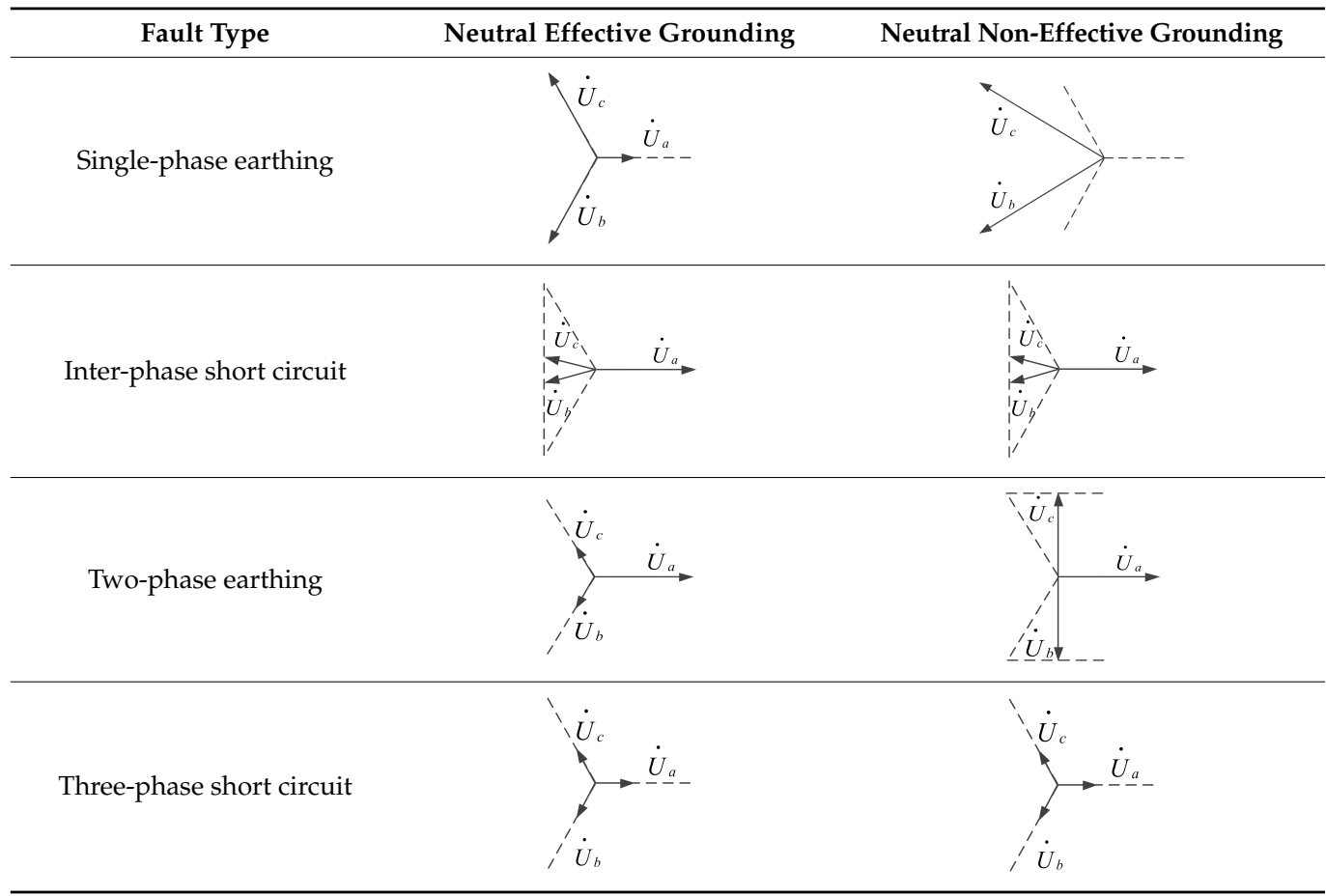

When fault propagates through transformer, the voltage eigenvector may change; it depends on the wiring form of the transformer. Take the $Y / \Delta$-11-type transformer as an example: when the fault propagates through this type of transformer, the voltage zero sequence component cannot pass, which leads to the changes of phase voltage eigenvector as shown in Table 3.

Table 3. Voltage eigenvector change after fault propagation.

\begin{tabular}{ccc}
$\begin{array}{c}\text { Fault Type } \\
\text { (Neutral Ground) }\end{array}$ & Eigenvector Diagram of Original Fault & $\begin{array}{c}\text { Eigenvector Diagram after Propagation } \\
\text { through Transformer }\end{array}$ \\
\hline Single-phase earthing (phase A) & & $\vdots$ \\
\hline Inter-phase short circuit (phase $\mathrm{B} \backslash \mathrm{C})$ & & $\vdots$ \\
\hline
\end{tabular}


It can be seen from Tables 2 and 3, when fault occurs, the voltage vector is not only reflected in the amplitude variation, but also in the phase angle variation. It is required that the VSSG can simulate different kinds of voltage sag/swell features to test the HVRT and LVRT capability of the grid-connected equipment.

\section{Main Circuit and Its Mathematical Model}

As shown in Figure 1, the proposed VSSG main circuit consists of step-up transformer, uncontrolled rectifier bridge, DC split capacitors, three-phase inverter circuit and LC lowpass filter. The step-up transformer is used to provide voltage swell margin. The midpoint of DC split capacitors is connected to the neutral line of the AC side so that the AC output main circuit becomes a three-phase four-wire system.

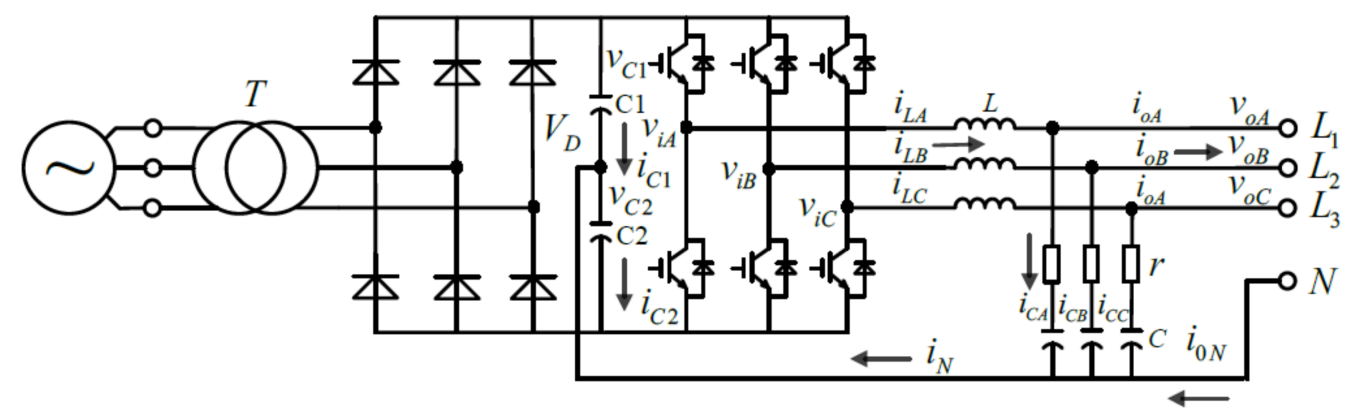

Figure 1. Main circuit of VSSG.

The symbols in Figure 1 and the following analysis are shown in Table 4.

Table 4. Symbols in the mathematical model.

\begin{tabular}{llll}
\hline Symbol & Meaning & Symbol & Meaning \\
\hline$L$ & filter inductor & $v_{C 1}$ & voltage on capacitor C1 \\
\hline$C$ & filter capacitor & $v_{C 2}$ & voltage on capacitor C2 \\
\hline$r$ & damping resistance & $v_{o A}, v_{o B}, v_{O C}$ & three-phase output voltages \\
\hline$V_{D}$ & DC-link voltage & $i_{o A}, i_{o B}, i_{O C}$ & three-phase output currents \\
\hline$i_{C A}, i_{C B}, i_{C C}$ & $\begin{array}{l}\text { Currents in Filter } \\
\text { capacitors }\end{array}$ & $v_{i A}, v_{i B}, v_{i C}$ & $\begin{array}{l}\text { three-phase output voltages } \\
\text { before filter }\end{array}$ \\
\hline$i_{L A}, i_{L B}, i_{L C}$ & $\begin{array}{l}\text { Currents through } \\
\text { inductors }\end{array}$ & $v_{r A}, v_{r B}, v_{r C}$ & $\begin{array}{l}\text { three-phase modulation } \\
\text { input voltages }\end{array}$ \\
\hline
\end{tabular}

The front circuit of the VSSG is composed of a step-up transformer and an uncontrolled rectifier. Under the ideal condition (the front circuit capacity satisfies the operation requirements and the AC supply voltage is stable), $V_{D}$ is constant, and the neutral voltage deviation is controlled to ensure that $\mathrm{N}$ is zero potential. Each phase output may be controlled independently and not affected by each other, which is the precondition for any phase to simulate voltage sag/swell and phase angle shift as a real three-phase four-wire low-voltage power supply network.

The three phases coupling relationship in 3-phase 3-wire and 3-phase 4-wire inverter circuit can be illustrated using topologies in Figures 2 and 3, respectively.

It can be seen from Figure $2 b$ that any phase voltage is affected by other two phases; there is a mutual coupling relationship between output voltages of 3 phases in the 3-phase 3-wire inverter circuit.

For a 3-phase 4-wire inverter circuit, by means of the neutral line connection and clamp control for the neutral voltage, the independence of each phase output circuit can be guaranteed as shown in Figure 3. 


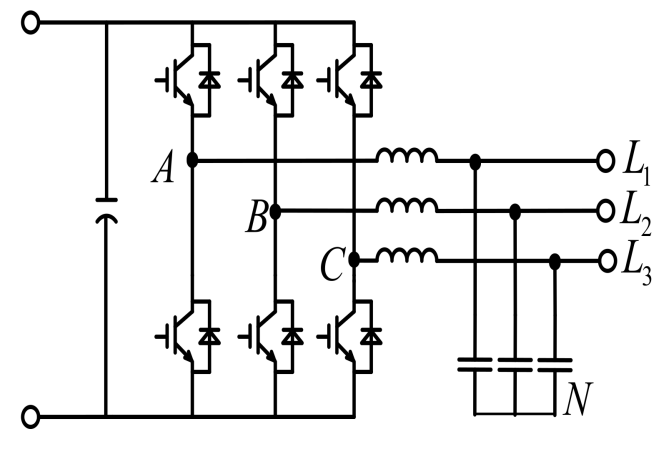

(a)

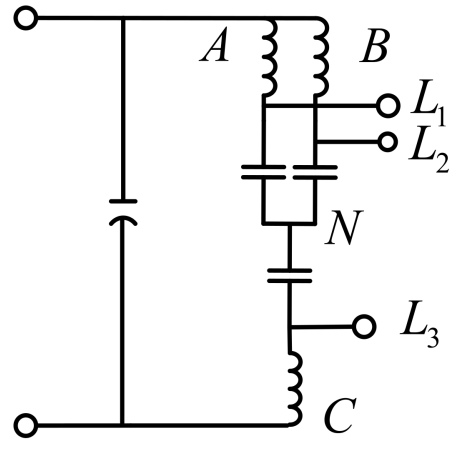

(b)

Figure 2. 3-phase 3-wire system topology. (a) Main circuit. (b) Simplified diagram of one working state.

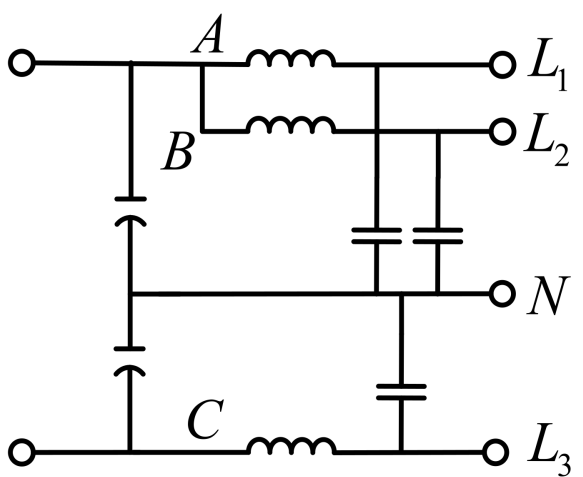

Figure 3. Simplified diagram of one working state of 3-phase 4-wire system topology.

Therefore, the main loop model of the VSSG proposed can be simplified to a singlephase inverter circuit as shown in Figure 4. The resistance $r$ of the low-pass filter is used to damp oscillation. Due to its small value, resistance $r$ can be ignored when analyzes the characteristics of the control system, and thus the relationships of phase current and voltage can be expressed as Equations (1)-(3) (take phase A as an example).

$$
\begin{gathered}
v_{i A}=v_{O A}+L \frac{d i_{L A}}{d t} \\
i_{L A}=i_{C A}+i_{O A} \\
i_{C A}=C \frac{d v_{O A}}{d t}
\end{gathered}
$$

From Equation (1) to Equation (3), the transfer function among $v_{O A}, i_{O A}$, and $v_{i A}$ can be deduced as Equation (4).

$$
v_{i A}(s)=\left(1+L C s^{2}\right) v_{O A}(s)+L s i_{O A}(s)
$$

According to the principle of SPWM, the transfer function between the modulation wave input $v_{r A}$ and output voltage $v_{i A}$ of inverter side is a constant.

$$
\frac{v_{i A}}{v_{r A}}=K_{P W M}
$$

In the above inverter circuit, $K_{P W M}$ is $V_{D} / 2$. By adjusting the modulation ratio $M$ in the control process, the amplitude of the modulation wave $v_{r A}$ is adjusted, and finally the amplitude of $v_{i A}$ is adjusted. 


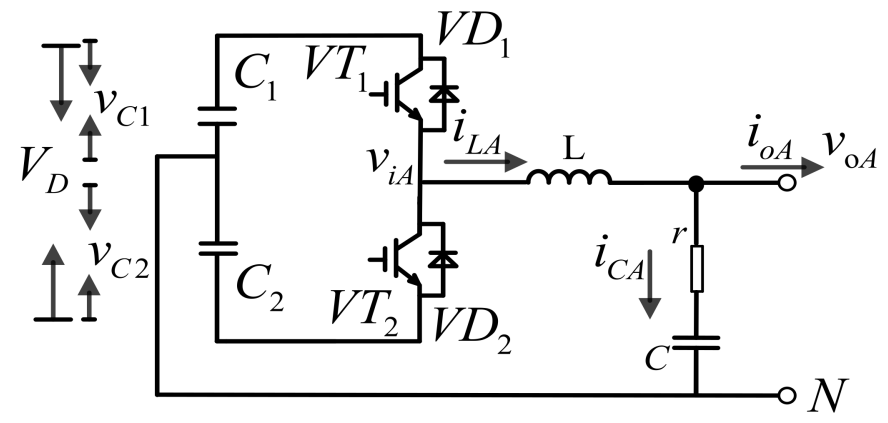

Figure 4. Equivalent single-phase inverter circuit.

Unlike the inverter with only voltage sag capability, the maximum modulation ratio $(M=1)$ in this case corresponds to the highest swell output voltage $U_{h}$, and the modulation ratio at the rated voltage of $400 \mathrm{~V}$ is about $400 / U_{h}$.

According to Equations (4) and (5), the open-loop system structure of the inverter circuit is as shown in Figure 5.

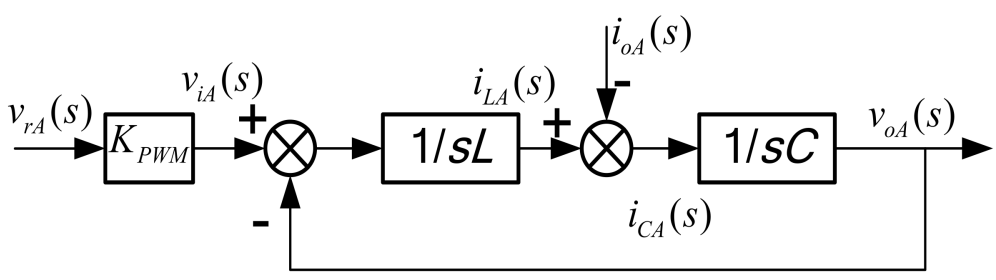

Figure 5. Single phase open loop block diagram of inverter.

The LC filter is designed according to the principles shown in Equations (6) and (7).

$$
\begin{aligned}
& 10 f_{r} \leq f_{c} \leq f_{s} / 10 \\
& f_{c}=1 /(2 \pi \sqrt{L C})
\end{aligned}
$$

where $f_{r}$ is the fundamental frequency of VSSG output voltage, $f_{c}$ is the resonant frequency of LC filter, and $f_{s}$ is the switching frequency of inverter circuit.

The filter inductance is designed to control its voltage drop less than $3 \%$, and to restrict the maximum current ripple in the meantime. The optimized design of the relevant parameters may be performed in combination with the Bode diagram of the corresponding transfer function, and details are not described herein.

\section{Control Strategy}

\subsection{Main Control Strategy}

For the inverter circuit above, the common dual closed-loop control strategy, namely the outer voltage control and the inner current control [32] is used. Corresponding control block diagram is shown in Figure 6.

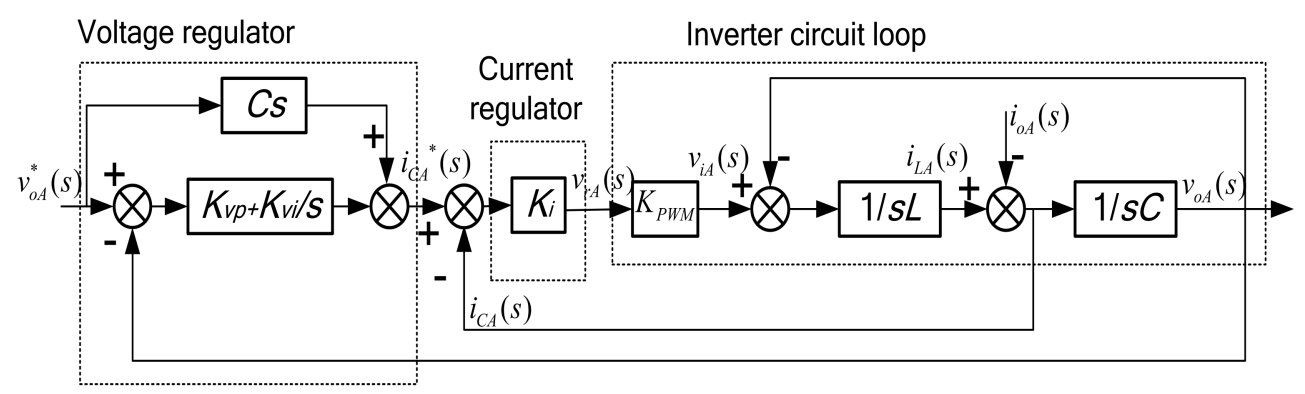

Figure 6. Double closed loop control strategy block diagram. 
The control model in Figure 6 includes a current feedback inner loop, a voltage feedback outer loop and a voltage feedforward loop. The inner loop of the current is used to suppress the oscillation of LC filter and improve the dynamic characteristics of the whole system. The filter capacitor current $i_{C A}$ is chosen as the control target, and the proportional controller can realize the expected control effect. $K_{i}$ is the proportional gain in the current regulator. The voltage feedback outer loop is designed to ensure that the output voltage $v_{O A}$ of VSSG follows the set value $v_{O A}^{*}$. The loop adopts the PI regulator, of which $K_{v p}$ is the proportional gain and $K_{v i}$ is the integral gain, while the PI regulator cannot realize no static error tracking control of the sine signal. Therefore, a load voltage feedforward loop is added to eliminate the error, and then the high precision tracking of the set value will be realized.

The transfer function from the set current value of inner loop to the feedback current value in Figure 6 can be written as:

$$
i_{C A}=\frac{K_{i} K_{P W M} C s}{L C s^{2}+K_{i} K_{P W M} C s+1} i_{C A}^{*}-\frac{L C s^{2}}{L C s^{2}+K_{i} K_{P W M} C s+1} i_{o A}
$$

The goals of the current controller are: (1) to reduce the impact of load current $i_{O A}$ on the output voltage in the required frequency band, which is reflected in the Bode diagram that the load current gain is as small as possible near the power frequency; (2) to take into account the dynamic response performance of the overall power supply, which is reflected that the frequency band is as wide as possible in the Bode diagram. When $K_{i}=5$, according to Equation (8), the relevant gain at frequency $50 \mathrm{~Hz}$ of the current loop is: $i_{C A} / i^{*}{ }_{C A}=1$, $i_{C A} / i_{O A}<0.001$. By simulation, it is verified that the above parameters can meet the expected control effect of the current controller.

According to Figure 6, the transfer function from the set voltage value to the feedback voltage value of outer loop is:

$$
\begin{aligned}
& v_{O A}=\frac{K_{i} K_{P W M} C s^{2}+K_{i} K_{v p} K_{P W M} s+K_{i} K_{v i} K_{P W M}}{L C s^{3}+K_{i} K_{P W M} C s^{2}+\left(1+K_{i} K_{v p} K_{P W M}\right) s+K_{i} K_{v i} K_{P W M}} v_{O A}^{*}- \\
& \frac{L s^{2}}{L C s^{3}+K_{i} K_{P W M} C s^{2}+\left(1+K_{i} K_{v p} K_{P W M}\right) s+K_{i} K_{v i} K_{P W M}} i_{o A}
\end{aligned}
$$

According to the Thevenin theorem, the above relational expression can be represented by the equivalent circuit depicted in Figure 7, where $G_{C} v^{*}{ }_{0 A}$ is a controllable voltage source, $Z(s)$ is the internal impedance of the inverter, and $Z_{L}$ is equivalent impedance of the load.

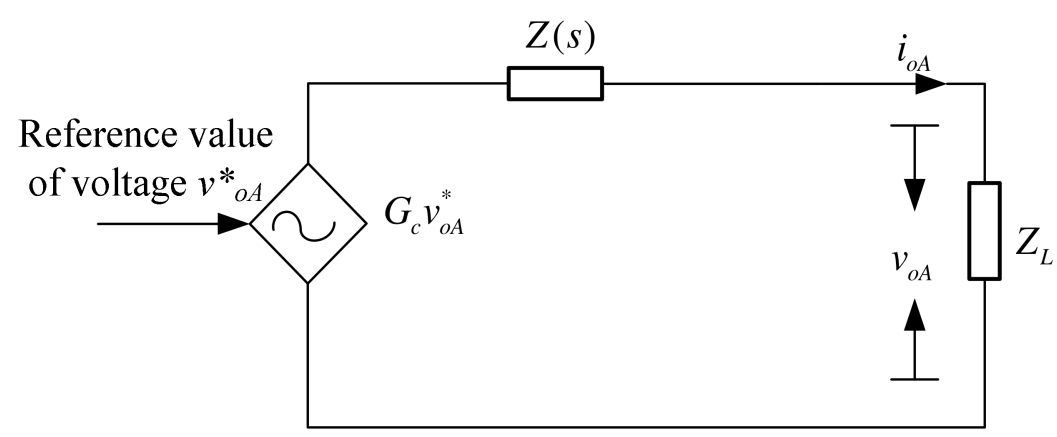

Figure 7. Thevenin's equivalent circuit of VSSG closed loop control.

The equation in Figure 7 can be expressed as:

$$
v_{o A}=G_{C}(s) v_{O A}^{*}-Z(s) i_{o A}
$$


According to Equations (9) and (10), the closed-loop voltage gain $G_{c}(s)$ and the output impedance $Z(s)$ of the inverter are as follows:

$$
\begin{aligned}
G_{c}(s) & =\frac{K_{i} K_{P W M} C s^{2}+K_{i} K_{v p} K_{P W M} s+K_{i} K_{v i} K_{P W M}}{L C s^{3}+K_{i} K_{P W M} C s^{2}+\left(1+K_{i} K_{v p} K_{P W M}\right) s+K_{i} K_{v i} K_{P W M}} \\
Z(s) & =\frac{L s^{2}}{L C s^{3}+K_{i} K_{P W M} C s^{2}+\left(1+K_{i} K_{v p} K_{P W M}\right) s+K_{i} K_{v i} K_{P W M}}
\end{aligned}
$$

It can be seen from Equation (12) that the output impedance of the inverter under closed-loop control is not only affected by the filter parameters, but also related to the adopted control strategy.

The VSSG is a power generator, and it is used to simulate the actual grid power, for which the output impedance $Z(s)$ should be inductive near $50 \mathrm{~Hz}$. Additionally, in order to suppress the high frequency harmonics of itself effectively, it should exhibit resistance characteristic in high frequency range.

The frequency-domain response curves of output impedance $Z(s)$ when the controller designed with different parameters are shown in Figure 8. Figure 8a shows the curves corresponding to different $K_{v p}$ when $K_{v i}=10$. The curves of b001, b01, b1, b10, and b100 are corresponding to $0.01,0.1,1,10$, and 100 of $K_{v p}$, respectively. Figure $8 \mathrm{~b}$ shows the curves corresponding to different $K_{v i}$ when $K_{v p}=1$. The curves of b1, b10, b100, and b1000 are corresponding to $1,10,100$, and 1000 of $K_{v i}$, respectively.

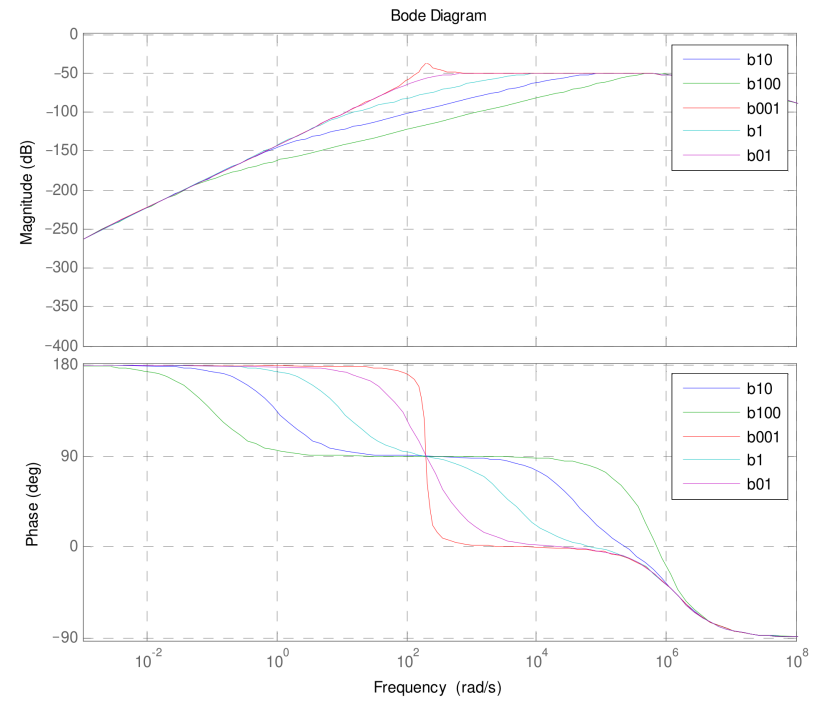

(a)

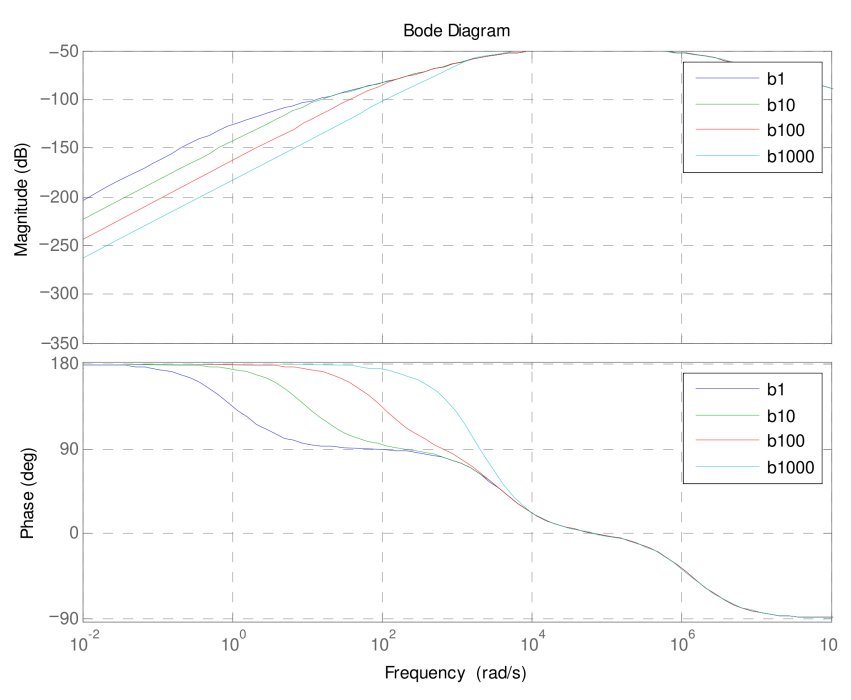

(b)

Figure 8. The frequency response curves of $Z(s)$ corresponding to different parameters. (a) The curves corresponding to different $K_{v p}$. (b) The curves corresponding to different $K_{v i}$.

It can be seen that when different parameters of the controller are applied, the output impedance characteristics exhibited are different at $50 \mathrm{~Hz}$. Therefore, when selecting the specific parameters of the controller, it is necessary to comprehensively ensure that the output impedance is inductive at $50 \mathrm{~Hz}$ and is resistive at the high frequency range, so as to effectively suppress the harmonics of the switching frequency band and meet the requirements of the VSSG.

When $K_{v p}=1$ and $K_{v i}=10$, the frequency response curve of the transfer function $G_{c}(s)$ corresponding to the VSSG closed-loop control is shown in Figure 9.

In fact, due to the zero deviation of the neutral current and the physical parameters difference of the capacitor itself, there is a problem of midpoint voltage drift in VSSG DC 
bus splitter capacitor, which will lead to the waveform distortion of output voltage and current, so the midpoint voltage drift must be controlled.

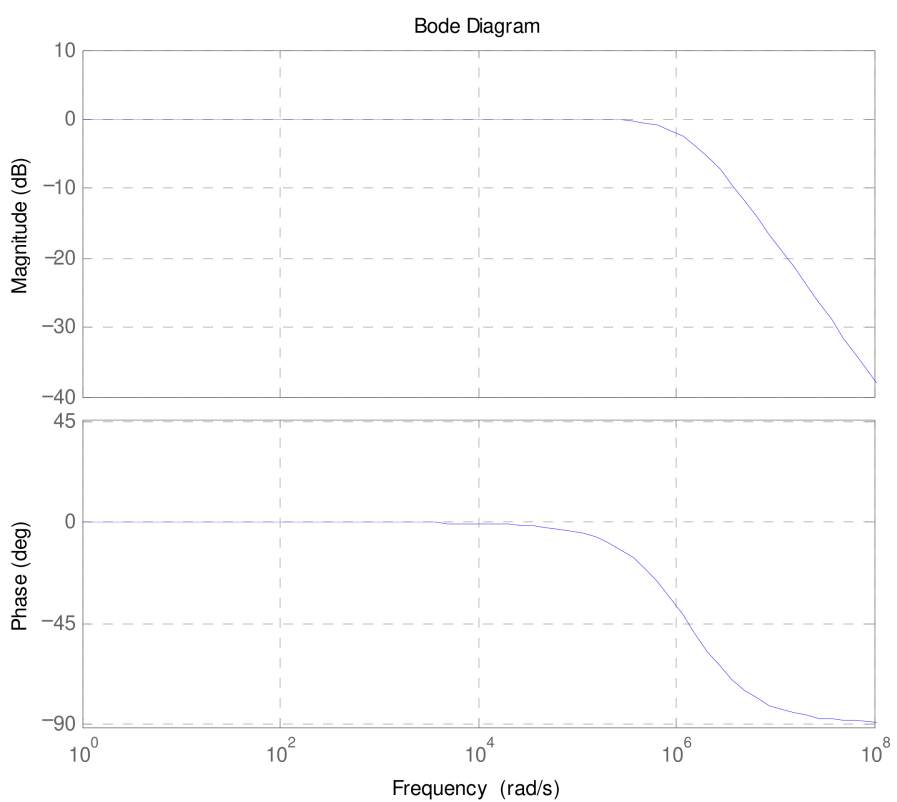

Figure 9. $G_{\mathcal{C}}(s)$ frequency response curve.

\subsection{Capacitor Voltage Deviation Control Strategy}

For this VSSG, a split capacitor voltage deviation control is added to the control strategy to settle the midpoint voltage drift, as shown in Figure 10. Specifically, the split capacitor voltage deviation signal is added to the given current signal so that the current fluctuation will be compensated, and then the voltage of the split capacitors be balanced. The basic working principle is that, according to the difference of the split capacitor voltage, the inverter generates a small DC current to charge or discharge the positive/negative capacitor to adjust the potential of the $\mathrm{N}$ point. Its control strategy is a simple proportional control.

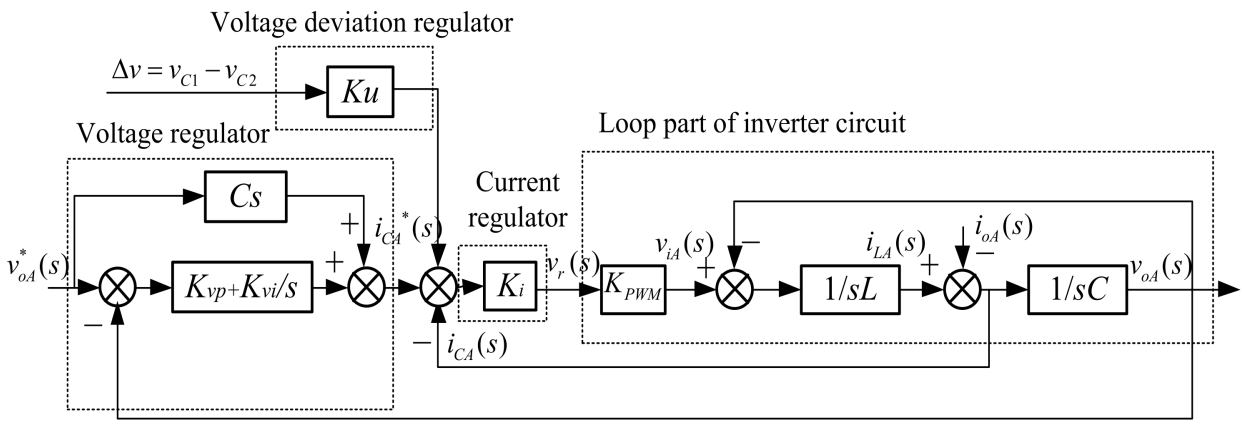

Figure 10. VSSG control block diagram with neutral voltage deviation control.

\section{Simulation}

In order to verify the feasibility of the VSSG scheme, the simulation model is built by Matlab/Simulink. The detail parameters of the simulation circuit are shown in Table 5, which are selected to match with the prototype as well as possible.

Specific simulation experiments are as follows:

(1) Three-phase voltage synchronous swell and sag;

(2) Single-phase voltage swell and sag;

(3) Single-phase voltage swell, sag and phase angle jumping. 
Table 5. Voltage eigenvector change after fault propagation.

\begin{tabular}{cc}
\hline Parameter & Value \\
\hline DC-link Voltage, $V_{D}$ & $900 \mathrm{~V}$ \\
Switching Frequency, $f_{s}$ & $6 \mathrm{kHz}$ \\
DC-link Capacitance, $C 1 / C 2$ & $800 \mu \mathrm{F}$ \\
Filter Capacitance, $C$ & $250 \mu \mathrm{F}$ \\
Filter inductance, $L$ & $1.7 \mathrm{mH}$ \\
Load Capacity & $8+\mathrm{j} 6 \Omega$ \\
Power Factor & 0.8 \\
\hline
\end{tabular}

The simulation results obtained are shown in Figure 11, the sag/swell duration is $50 \mathrm{~ms}$ (from $0.21 \mathrm{~s}$ to $0.26 \mathrm{~s}$ ). It can be seen from Figure 11a,c that the VSSG can realize the simulation of three-phase voltage synchronous swell and sag, the transition time is short and the waveforms are not distorted. Figure 11b,d show the VSSG can also realize the simulation of single-phase voltage swell and sag, and the amplitude and phase of other phases remain unchanged. Figure 11e shows the VSSG can realize the simulation of singlephase phase angle jumping without interfering other phases. The independent voltage control for any phase is achieved. The above simulation results verified the feasibility of the VSSG design scheme.
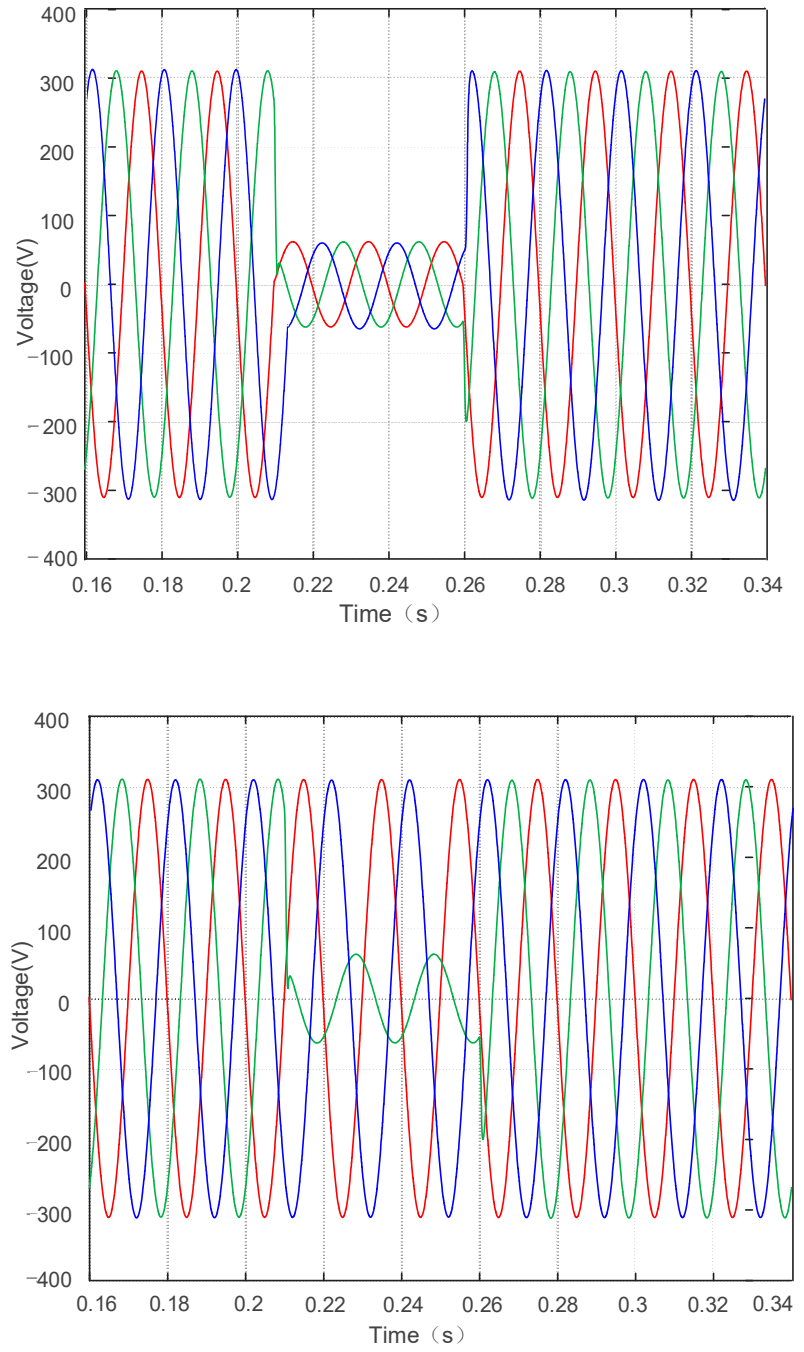

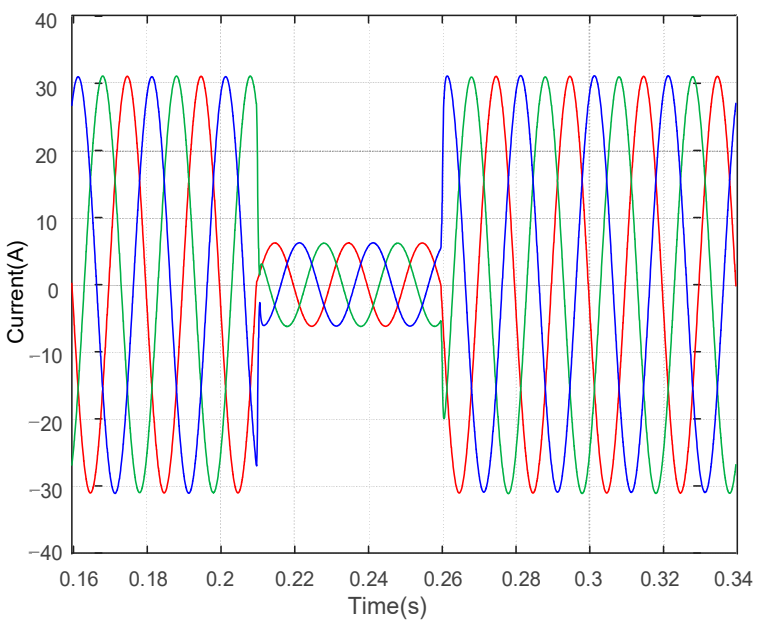

(a)

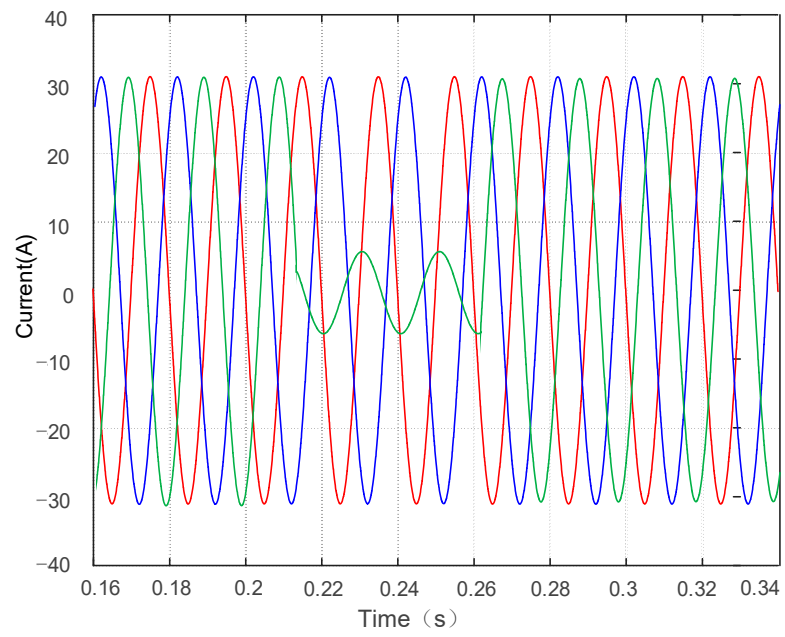

(b)

Figure 11. Cont. 

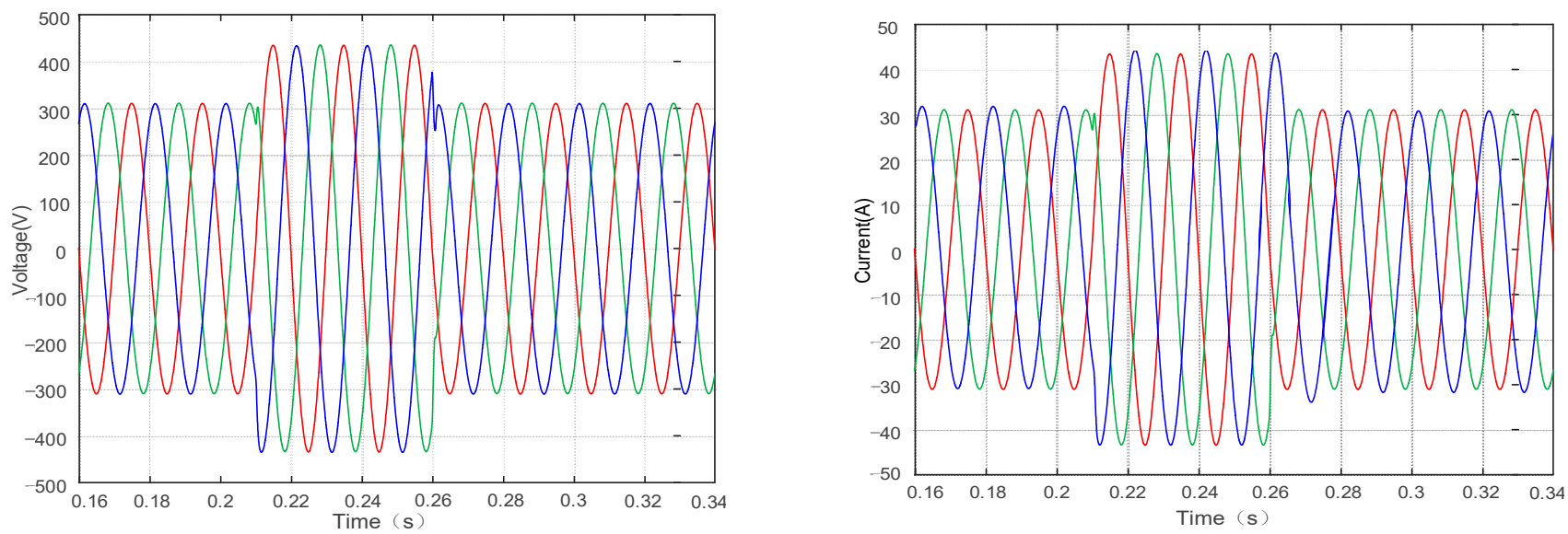

(c)
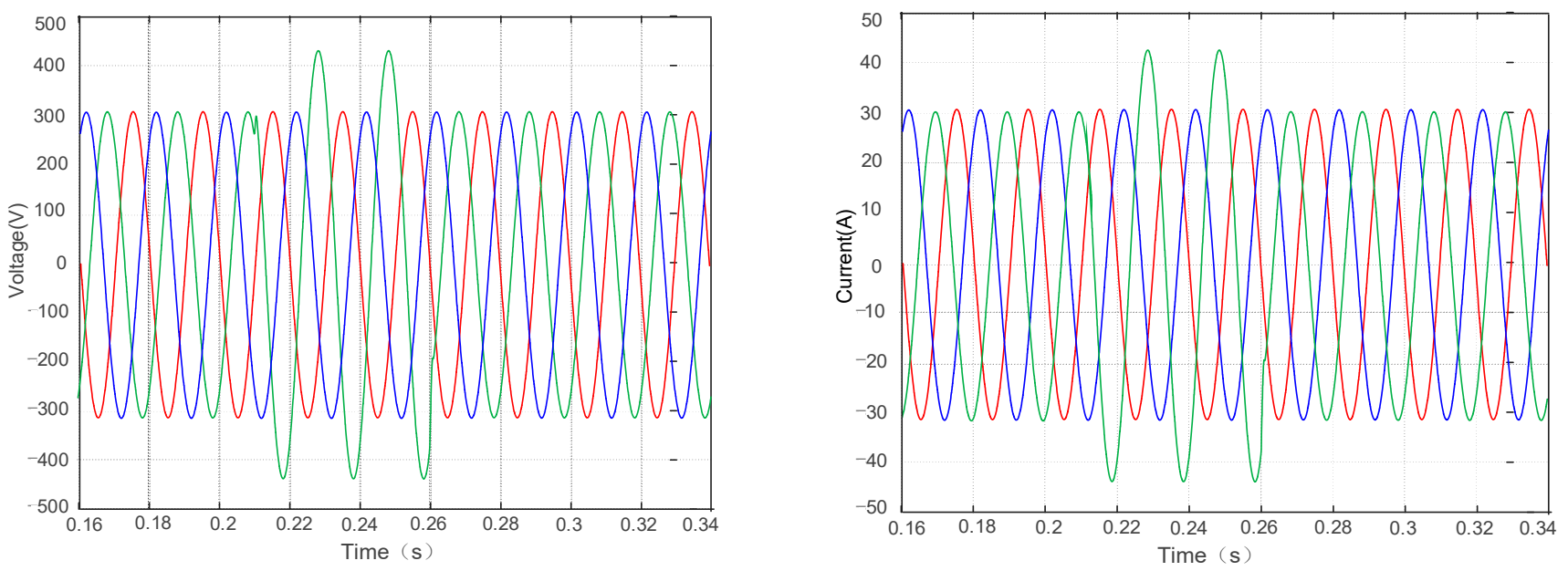

(d)
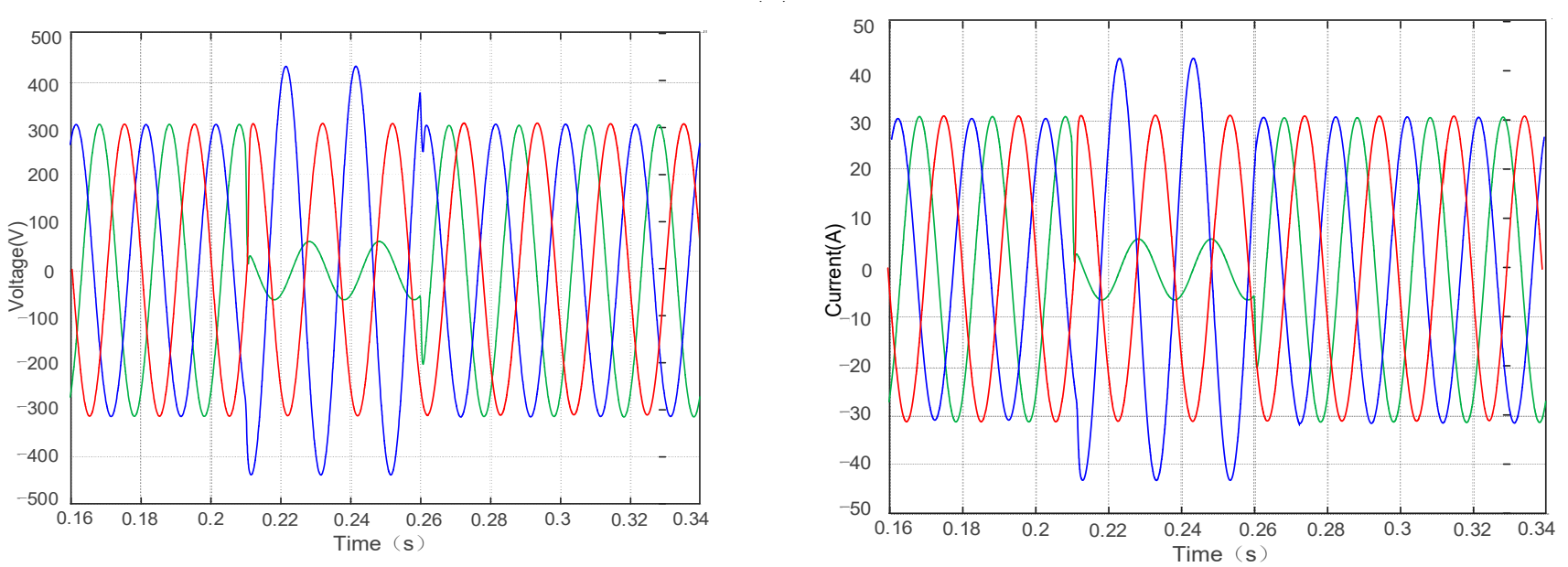

(e)

Figure 11. Simulation voltage waveforms. (a) Three-phase sags to $20 \%(0.2 \mathrm{pu})$. (b) Single-phase sags to $20 \%(0.2 \mathrm{pu})$. (c) Three-phase swells to $140 \%$ (1.4 pu). (d) Single-phase swells to $140 \%$ (1.4 pu). (e) Phase A swells to $140 \%$ (1.4 pu), phase $\mathrm{B}$ sags to $20 \%(0.2 \mathrm{pu})$, and phase $\mathrm{C}$ phase angle jumping $60^{\circ}$. 


\section{Experimental Results}

A test prototype is set up, which can support $11 \mathrm{~kW}$ constant power load with $400 \mathrm{~V} / 25 \mathrm{~A}$ rated voltage/current. When the minimum output voltage is $20 \%$ of the rating, the maximum output current will increase to five times the rated value, i.e., $125 \mathrm{~A}$. The designed maximum output voltage is $140 \%$ of the rated value, i.e., $560 \mathrm{~V}$; the step-up transformer is an autotransformer. In order to make full use of DC voltage, the output voltage of the autotransformer is adjusted to $560 \mathrm{~V}$. Table 6 shows the parameters of the test prototype.

Table 6 . The test prototype parameters.

\begin{tabular}{ccc}
\hline Component Name & Component Parameters & Max. Operating Parameters \\
\hline Step-up Transformer & $380 \mathrm{~V} / 660 \mathrm{~V} / 20 \mathrm{kVA}$ & $380 / 560 \mathrm{~V} / 15 \mathrm{kVA}$ \\
Rectifier Bridge & $150 \mathrm{~A} / 1200 \mathrm{VDC}$ & $25 \mathrm{~A} / 760 \mathrm{VDC}$ \\
Inverter Bridge & $150 \mathrm{~A} / 1200 \mathrm{VDC}$ & $125 \mathrm{~A} / 760 \mathrm{VDC}$ \\
DC-link Capacitance, C1/C2 & $800 \mu \mathrm{F} / 450 \mathrm{VDC}$ & $800 \mu \mathrm{F} / 440 \mathrm{VDC}$ \\
Filter Capacitance, C & $250 \mu \mathrm{F} / 1000 \mathrm{VAC}$ & $250 \mu \mathrm{F} / 560 \mathrm{VAC}$ \\
Filter inductance, $\mathrm{L}$ & $1.7 \mathrm{mH} / 150 \mathrm{~A}$ & $1.7 \mathrm{mH} / 125 \mathrm{~A}$ \\
\hline
\end{tabular}

Figure 12 are the test output waveforms of a $5 \mathrm{~kW}$ load $(\cos \varphi=0.8)$. It can be observed from Figure 12, the generated voltage swell and sag by the VSSG can all achieve rapid response. The output voltage waveform can be completed to switch in a very short time. The voltage amplitude and phase of any phase can be fully controlled independently.

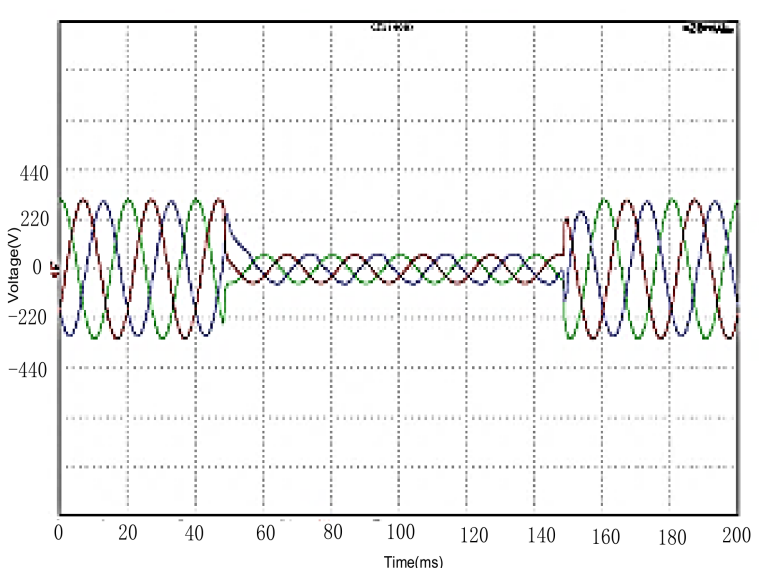

(a)

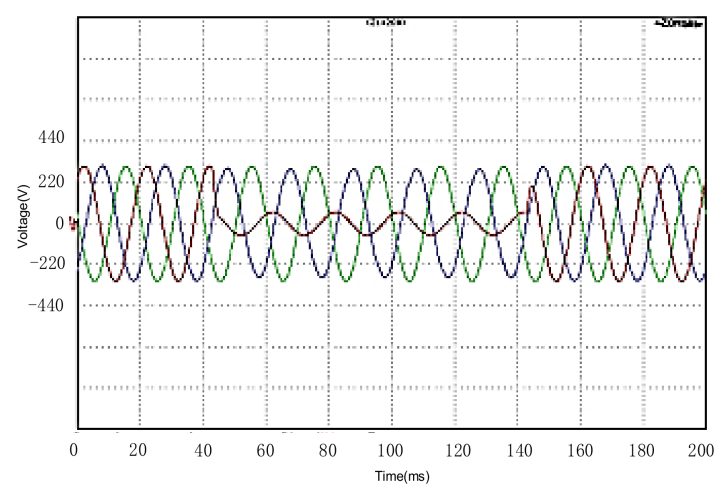

(c)

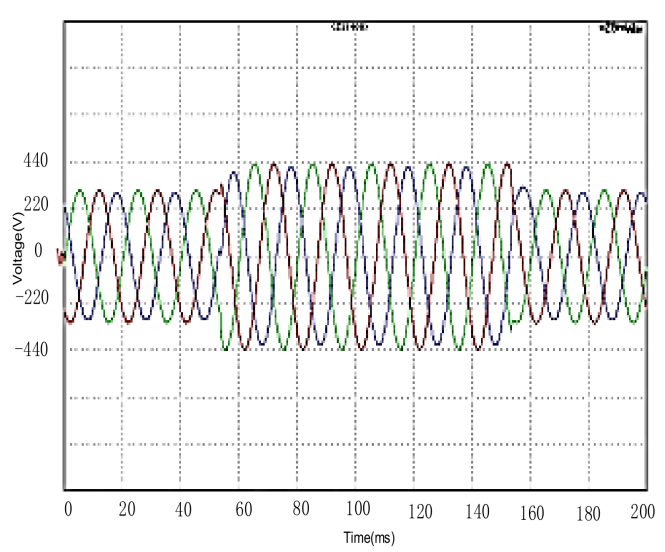

(b)

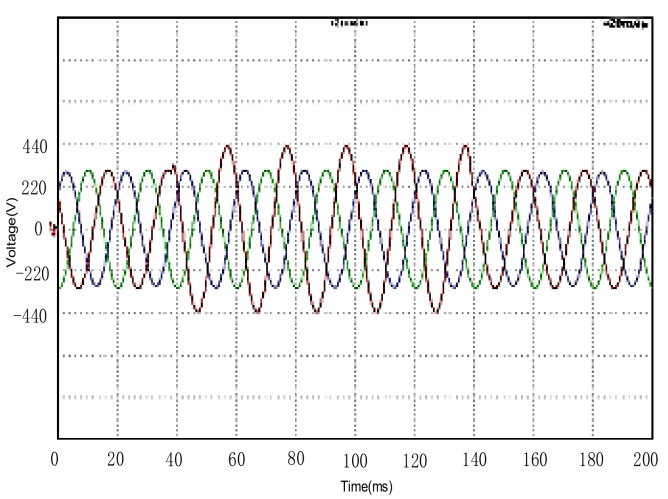

(d)

Figure 12. Cont. 


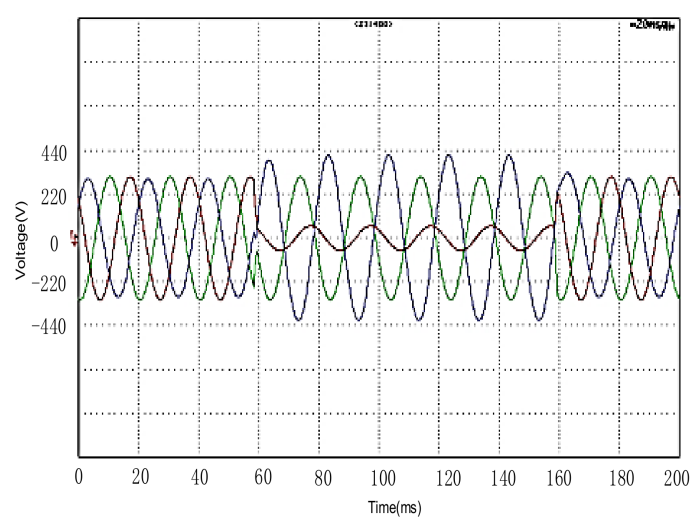

(e)

Figure 12. Test waveforms. (a) Three-phase sags to $20 \%$ (0.2 pu). (b) Three-phase swells to $140 \%$. (c) Single-phase sags to $20 \%$ (0.2 pu). (d) Single-phase swells to $140 \%$ (1.4 pu). (e) Phase A swells to $140 \%$ (1.4 pu), phase B sags to $20 \%(0.2 \mathrm{pu})$, and phase $\mathrm{C}$ phase angle jumping $60^{\circ}$.

From the above experiments, it is shown that the VSSG proposed in this paper can realize generating voltage swell, sag, and phase angle jumping of any phase, and also realize stepless adjustment within the set voltage range. The previous theoretical study is verified.

\section{Conclusions}

This paper proposes a multi-mode voltage sag/swell generator (VSSG) with a simple and reliable main circuit, which is based on the common three-phase inverter circuit and SPWM control. Cooperated with the designed control loops, the VSSG achieves to generate any kinds of voltage sag, swell, and phase angle jumping, and support step-less adjustment for voltage sag/swell depth, duration, and angle jumped. With high precision and fast response, the simulation and experimental results verify that it can accurately simulate the various types of power grid fault. Moreover, the VSSG is developed according to the standard of common multi-mode voltage sag/swell generator, which can simulate the power grid voltage sag and swell phenomena under IEEE 1159 and IEC standards. The VSSG has good practicality, which can be used as a power supply for testing various electrical equipment.

Author Contributions: Conceptualization, Q.H. and P.H.; Methodology, X.W.; Simulation, M.W.; Experiment test, X.L. and W.H.; Writing—original draft preparation, X.W.; Writing—review and editing, P.H.; and Funding acquisition, Q.H. All authors have read and agreed to the published version of the manuscript.

Funding: This research was funded by the Zhejiang Natural Science Foundation of China, Grant Number LY20E070004.

Conflicts of Interest: The authors declare no conflict of interest.

\section{References}

1. Tallam, R.M.; Lukaszewski, R.A. Voltage sag and unbalance generator for power quality testing of adjustable speed drives. In Proceedings of the IEEE Energy Conversion Congress and Exposition, Denver, CO, USA, 15-19 September 2013; pp. 4565-4571.

2. $\mathrm{Xu}, \mathrm{Y}$.; Lu, W.; Wang, K.; Li, C.; Aslam, W. Sensitivity of Low-Voltage Variable-Frequency Devices to Voltage Sags. IEEE Access 2018, 7, 2068-2079. [CrossRef]

3. Han, Q.; Zhu, K.; Shi, W.; Wu, K.; Chen, K. Research on the supercapacitor support schemes for LVRT of variable-frequency drive in the thermal power plant. In Proceedings of the EEEP 2017 The Second International Conference on Energy Engineering and Environmental Protection, Shanya, China, 20-22 November 2017; pp. 1-8.

4. Abdel-Baqi, O.; Nasiri, A. Series Voltage Compensation for DFIG Wind Turbine Low-Voltage Ride-Through Solution. IEEE Trans. Energy Convers. 2011, 26, 272-280. [CrossRef] 
5. Zeng, R.; Nian, H.; Zhou, P. A three-phase programmable voltage sag generator for low voltage ride-through capability test of wind turbines. In Proceedings of the IEEE Energy Conversion Congress and Exposition (ECCE), Atlanta, GA, USA, 12-16 September 2010; pp. 305-311.

6. Liu, Q.; Li, Y. An Inductive Filtering-Based Parallel Operating Transformer with Shared Filter for Power Quality Improvement of Wind Farm. IEEE Trans. Power Electron. 2020, 35, 9281-9290. [CrossRef]

7. Liu, Q.; Li, Y.; Hu, S.; Luo, L. Power quality improvement using controllable inductive power filtering method for industrial DC supply system. Control. Eng. Pract. 2019, 83, 1-10. [CrossRef]

8. Hajizadeh, A.; Golkar, M.A.; Feliachi, A. Voltage Control and Active Power Management of Hybrid Fuel-Cell/Energy-Storage Power Conversion System under Unbalanced Voltage Sag Conditions. IEEE Trans. Energy Convers. 2010, 25, 1195-1208. [CrossRef]

9. Tafti, H.D.; Maswood, A.I.; Konstantinou, G.; Townsend, C.D.; Acuna, P.; Pou, J. Flexible Control of Photovoltaic Grid-Connected Cascaded H-Bridge Converters During Unbalanced Voltage Sags. IEEE Trans. Ind. Electron. 2018, 65, 6229-6238. [CrossRef]

10. Shabestary, M.M.; Mohamed, Y.A.I. Asymmetrical Ride-Through and Grid Support in Converter-Interfaced DG Units under Unbalanced Conditions. IEEE Trans. Ind. Electron. 2019, 66, 1130-1141. [CrossRef]

11. Gabe, I.J.; Gründling, H.A.; Pinheiro, H. Design of a voltage sag generator based on impedance switching. In Proceedings of the IECON 2011-37th Annual Conference on IEEE Industrial Electronics Society, Melbourne, VIC, Australia, 7-10 November 2011; pp. 3140-3145.

12. Chung, Y.H.; Kwon, G.H.; Park, T.B.; Lim, G.Y. Voltage sag and swell generator with thyristor controlled reactor. In Proceedings of the International Conference on Power System Technology, Kunming, China, 13-17 October 2002; pp. $1933-1937$.

13. Yang, Y.; Blaabjerg, F.; Zou, Z. Benchmarking of Voltage Sag Generators. In Proceedings of the IECON 2012-38th Annual Conference on IEEE Industrial Electronics Society, Montreal, QC, Canada, 25-28 October 2012; pp. 943-948.

14. Collins, E.R.; Morgan, R.L. A three-phase sag generator for testing industrial equipment. IEEE Trans. Power Deliv. 1996, 11, 526-532. [CrossRef]

15. Kumsuwan, Y.; Boonmee, C.; Premrudeepreechacharn, S. Implementation of a 1-kVA programmable balanced three-phase voltage sag generator. In Proceedings of the 2009 6th International Conference on Electrical Engineering/Electronics, Computer, Telecommunications and Information Technology, Pattaya, Thailand, 6-9 May 2009; pp. 46-49.

16. Ma, Y.; Karady, G.G. A single-phase voltage sag generator for testing electrical equipments. In Proceedings of the 2008 IEEE/PES Transmission and Distribution Conference and Exposition, Chicago, IL, USA, 21-24 May 2009; pp. 1-5.

17. Wessels, C.; Lohde, R.; Fuchs, F.W. Transformer based voltage sag generator to perform LVRT and HVRT tests in the laboratory. In Proceedings of the of 14th International Power Electronics and Motion Control Conference EPE-PEMC 2010, Ohrid, Macedonia, 6-8 September 2010; pp. T11-T18.

18. Senturk, O.S.; Hava, A.M. A Simple Sag Generator Using SSRs. IEEE Trans. Ind. Appl. 2012, 48, 172-180. [CrossRef]

19. İnc1, M.; Demırdelen, T.; Tan, A.; Köroğlu, T.; Cuma, M.U.; Bayindir, K.Ç.; Tümay, M. A novel low cost sag/swell generator. In Proceedings of the 2015 IEEE 6th International Symposium on Power Electronics for Distributed Generation Systems (PEDG), Aachen, Germany, 22-25 June 2015; pp. 1-4.

20. Chung, Y.H.; Kwon, G.H.; Park, T.B.; Kim, H.J.; Moon, J.I. Voltage sag, swell and flicker generator with series injected inverter. In Proceedings of the IEEE Power Engineering Society General Meeting, San Francisco, CA, USA, 16 June 2005; pp. 1308-1313.

21. Chung, Y.H.; Kwon, G.H.; Park, T.B.; Kim, H.J.; Jeon, Y.S. Voltage sag and swell generator with series injected inverter for the KCPP. In Proceedings of the 2004 International Conference on Power System Technology, Singapore, 21-24 November 2004; pp. 1589-1594.

22. Oranpiroj, K.; Premrudeepreechacharn, S.; Ngoudech, M.; Muangjai, W.; Yingkayun, K.; Boonsai, T. The 3-phase 4-wire voltage sag generator based on three dimensions space vector modulation in abc coordinates. In Proceedings of the 2009 IEEE International Symposium on Industrial Electronics, Seoul, Korea, 5-8 July 2009; pp. 275-280.

23. Muangjai, W.; Premrudeepreechacharn, S.; Higuchi, K.; Oranpiroj, K.; Jantee, W. An implementation algorithm of a carrier-based PWM technique for three-phase four-leg voltage sag generator with microcontroller. In Proceedings of the 2013 IEEE 10 th International Conference on Power Electronics and Drive Systems (PEDS), Kitakyushu, Japan, 22-25 April 2013 ; pp. 852-855.

24. Daychosawang, K.; Kumsuwan, Y. Balanced and unbalanced three-phase voltage sag generator for testing electrical equipment. In Proceedings of the IEEE 2014 11th International Conference on Electrical Engineering/Electronics, Computer, Telecommunications and Information Technology (ECTI-CON), Nakhon Ratchasima, Thailand, 14-17 May 2014; pp. 1-6.

25. Wu, K.; Han, Q.; Huang, X.; Quan, Y. Research on a Three-Phase Voltage Sag and Swell Generator Based on PWM Technology. Power Electron. 2015, 49, 56-58. (In Chinese)

26. Han, Y.; Feng, Y.; Yang, P.; Xu, L.; Xu, Y.; Blaabjerg, F. Cause Classification of Voltage Sag and Voltage Sag Emulators and Applications: A Comprehensive Overview. IEEE Access 2020, 8, 1922-1934. [CrossRef]

27. Cardenas, R.; Juri, C.; Pena, R.; Clare, J.; Wheeler, P. Analysis and Experimental Validation of Control Systems for Four-Leg Matrix Converter Applications. IEEE Trans. Ind. Electron. 2012, 59, 141-153. [CrossRef]

28. Díaz, M.; Cárdenas, R.; Soto, G. 4-wire Matrix Converter based voltage sag/swell generator to test LVRT in renewable energy systems. In Proceedings of the IEEE 2014 Ninth International Conference on Ecological Vehicles and Renewable Energies (EVER), Monte-Carlo, Monaco, 25-27 March 2014; pp. 1-10.

29. Díaz, M.; Cárdenas, R.; Rojas, F.; Clare, J. 3-Phase 4-wire matrix converter-based voltage sag/swell generator to test low-voltage ride through in wind energy conversion systems. IET Power Electron. 2014, 7, 3116-3125. [CrossRef] 
30. Bollen, M.H.J. Algorithms for characterizing measured three-phase unbalanced voltage dips. IEEE Trans. Power Deliv. 2003, 18, 937-944. [CrossRef]

31. Didden, M.; de Jaeger, E.; D'Haeseleer, W.; Belmans, R. How to connect a voltage sag-measuring device: Phase to phase or phase to neutral. IEEE Trans. Power Deliv. 2005, 20, 1174-1181. [CrossRef]

32. Zhou, L.; Jian, X.; Zhang, K.; Shi, P. A High Precision Multiple Loop Control Strategy for Three Phase PWM Inverters. In Proceedings of the IECON 2006 32nd Annual Conference on IEEE Industrial Electronics, Paris, France, 6-10 November 2006; pp. 1781-1786. 